\title{
Studi Kelayakan Pekerjaan Pemilihan Zona Produksi dan Squeeze off Cementing pada Sumur MY05
}

\author{
Novrianti ${ }^{1}$ \\ ${ }^{1}$ Universitas Islam Riau
}

\begin{abstract}
Abstrak
Meningkatnya water cut pada sumur MY05 menyebabkan terjadinya penurunan produksi minyak. Untuk mengatasi masalah tersebut, perlu dilakukan pekerjaan squeeze off pada zona perforasi yang mempunyai kontribusi produksi minyak yang rendah dan potensi produksi air yang tinggi. Setelah pekerjaan squeeze off selesai, selanjut dapat dilakukan pekerjaan shot top perforation (STP) untuk membuka zona produksi supaya produksi minyak dapat produksi. Pemilihan lapisan sand 1440' sebagai target perkerjaan squeeze off dan STP berdasarkan jumlah cadangan minyak yang tersisa (remaining oil reserve). Selain itu studi keekonomian juga dilakukan untuk mengetahui tingkat kelayakan proyek. Hasil kedua pekerjaan tersebut mengindikasikan adanya peningkatan produksi minyak sebesar 405 BOPD dan berkurang nya nilai water cut menjadi $76 \%$. Hasil analisa keekonomian menunjukkan bahwa pekerjaan tersebut sangat ekonomis untuk dilakukan.
\end{abstract}

Kata kunci: Squeeze off, Shot top perforation, Water cut, Economic evaluation

Corresponding Author: novrianti@eng.uir.ac.id

\section{PENDAHULUAN}

Commingle completion merupakan tipe produksi yang mengangkat hidrokarbon lebih dari satu lapisan reservoir pada suatu sumur migas. (Zulhendra, 2008). Meskipun diproduksi dari beberapa lapisan, seiring dengan berjalannya waktu penurunan produksi tetap akan terjadi pada sumur commingle. Adapun penyebab terjadinya penurunan produksi tersebut antara lain sumur tidak memiliki cukup tekanan untuk mengalirkan fluida ke permukaan, adanya kerusakan formasi, nilai water cut yang tinggi, dan fasilitas produksi yang sudah tua (Daneshy, A. A, 2006). Optimasi produksi dapat dilakukan dengan mengetahui alokasi produksi masing - masing lapisan yang diproduksi serta pengaruh dari karakteristik dan reservoir lapisan (Engler, T. W, et al, 2004).

Dengan berjalannya waktu, sumur dengan komplesi commingle juga akan mengalami penurunan produksi. Menurut Zulhendra (2008), masalah yang terjadi pada sumur yang memproduksikan minyak dari dua lapisan berbeda menggunakan tubing yang sama adalah tekanan dasar sumur yang tidak cukup besar untuk mengalirkan fluida ke permukaan karena adanya kerusakan formasi, nilai water cut yang cukup tinggi, serta fasilitas produksi yang tidak memadai. Oleh karena, itu perlu diketahui kontribusi produksi dari masing masing lapisan supaya produksi dapat berlangsung dengan optimal.

Menurunnya produksi minyak karena terproduksinya air dalam jumlah yang banyak pada sumur commingle completion dapat diatasi dengan mengevaluasi lapisan dan menutup zona tersebut dengan cara squeeze cementing. Squeeze cementing adalah salah satu dari pekerjaan ulang sumur yang bertujuan menutup lubang perforasi yang sudah ada dan memperbaiki kualitas bonding cement yang buruk. (Adams and Charrier, 1985). Tujuan utama dari squeeze cementing adalah:

1. Memperbaiki primary cementing

2. Menurunkan water oil ratio, water gas ratio atau gas oil ratio

3. Memblok zona yang tidak diinginkan

4. Menutup formasi yang sudah tidak produktif lagi

5. Menutup zona lost circulation

6. Memperbaiki kebocoran yang terjadi pada casing. 
Novrianti/JEEE Vol. 6 No. 2/2017

Membuka lapisan yang masih memiliki cadangan ekonomis dengan cara perforasi dapat dilakukan untuk meningkatkan produksi pada sumur commingle. Perforasi merupakan pekerjaan pembuatan lubang pada dinding sumur (casing dan lapisan semen) sehingga tercipta jalur komunikasi lubang sumur dengan formasi (P.Roberts, 1982). Shot top perforation adalah salah satu upaya untuk mengoptimalkan produksi suatu sumur.(P.Roberts, 1982). Shot Top Perforation bertujuan untuk membuka kembali lapisan paling atas yang sebelumnya sudah diproduksikan namun tidak lagi produktif atau tidak bernilai ekonomis. Shot top perforation dapat dilakukan apabila penurunan produksi sumur terjadi karena water cut yang tinggi. (Engler et al., 2004). Terdapat beberapa faktor yang harus dipertimbangkan sebelum melakukan suatu pekerjaan shot top perforation yaitu:

1. Lapisan memiliki cadangan minyak yang cukup besar sehingga masih layak untuk diproduksikan kembali.

2. Sumur tidak mempunyai masalah selain penurunan produksi yang disebabkan oleh produktivitas lapisan yang sudah mengalami decline.

3. Sumur masih memiliki interval lapisan yang masih produktif.

Analisis ekonomi perlu dilakukan untuk mengetahui kelayakan pekerjaan squeeze cementing dan shot top perforation yang dilakukan pada sumur tersebut. Net Present Value (NPV), Internal Rate of Return (IRR), Discounted Profit to Investment Ratio (DPIR), dan Pay Out Time (POT) merupakan parameter-parameter keekonomian yang sering digunakan untuk mengetahui dari suatu proyek.. Suatu proyek dapat dikatakan layak apabila NPV bernilai positif dan IRR bernilai lebih besar dari Minimum Attractive Rate of Return (MARR), DPIR $>1$, dan POT yang lebih kecil dari umur proyek.(Partowidagdo, 2002).

Sumur MY05 merupakan sumur produksi dengan interval perforasi pada kedalaman $1538 \mathrm{ft}-1548 \mathrm{ft}, 1548 \mathrm{ft}-1557$ ft, $1564 \mathrm{ft}-1571 \mathrm{ft}$ untuk lapisan Bekasap1440 dan, $1579 \mathrm{ft}-1583 \mathrm{ft}, 1586 \mathrm{ft}-1593 \mathrm{ft}, 1600 \mathrm{ft}-1610 \mathrm{ft}, 1613 \mathrm{ft}-1619$ $\mathrm{ft}$ untuk lapisan Bekasap1460. Sumur ini mengalami penurunan produksi minyak karena terjadinya peningkatan water cut (saat ini water cut 97\%). Oleh karena itu perlu didesain pekerjaan squeeze cementing untuk menutup interval perforasi yang tidak produktif, dan menentukan lapisan yang memiliki remaining reserve paling besar untuk diproduksi dengan cara melakukan perforasi pada lapisan tersebut. Studi ini bertujuan untuk menganalisis keberhasilan pekerjaan squeeze off dan shot top perforation berdasarkan sisi keekonomian pekerjaan tersebut.

\section{METODE}

Sebelum melakukan squeeze off \& shot top perforation, cadangan yang masih tersisa (Remaining Reserve) pada lapisan reservoir sumur tersebut perlu diperhitungkan serta dipertimbangkan. Nilai Remaining Reserve dapat dihitung dengan persamaan sebagai berikut:

$$
\text { Remaining Reserve (RR) } \quad=O O I P-N p
$$

Data injectivity test digunakan dalam melakukan pekerjaan squeeze cementing untuk menentukan jenis formasi loss, moderate dan tight. Data injectivity index ini dapat digunakan untuk menentukan desain semen serta tekanan pemompaan bubur semen agar memperoleh hasil squeeze yang bagus. Squeeze cementing pada sumur MY05 dilakukan dengan menggunakan metode open ended dengan estimasi top of cement (TOC) berjarak $50 \mathrm{ft}$ di atas zona perforasi paling atas. Persamaan yang digunakan dalam design squeeze cementing adalah (Bourgoyne, A. T., et al, 1991):

$$
\begin{aligned}
& \text { Cement In Casing (CIC) = Casing Capacity } 7 \text { ”x (OE Tubing }- \text { Est. TOC) } \\
& \text { Cement In Formation = Cement Slurry/Hole x Total Hole x 0,1781 bbl/cuft } \\
& \text { Total cement slury } \quad=\text { CIC }+ \text { CIF } \\
& \text { Jumlah cement yang dibutuhkan }=\frac{\text { Total Slurry } \times 5.615^{\text {cuft } / \mathrm{bbl}}}{\text { Yield Point }} \\
& \text { Air bersih yang dibutuhkan = Jumlah semen } \times \frac{4,94 \mathrm{gal} / \mathrm{sack}}{42 \mathrm{bbl} / \mathrm{sack}} \\
& \text { Fracture pressure } \quad=\text { gradient fracture } \mathrm{x} \text { top perforation }
\end{aligned}
$$


Jumlah aditif yang digunakan dalam design squeeze cementing pada sumur MY05 tercantum pada table 1 berikut:

Tabel 1. Aditif design squeeze cementing

\begin{tabular}{lc}
\hline Aditif & Volume (bbl) \\
\hline Hallad & 0,5 \\
\hline CFR & 0,25 \\
\hline HR & 0,4 \\
\hline D air & 0,4 \\
\hline
\end{tabular}

Data yang diperoleh dari Injectivity test sangat berpengaruh terhadap penentuan keberhasilan pekerjaan squeeze cementing, karena data yang diperoleh akan digunakan untuk mengetahui informasi mengenai lapisan atau daerah yang akan di squeeze, kesanggupan formasi dalam menerima fluida serta nilai tekanan pemompaan bubur semen dan desain bubur semen.

Setelah melakukan design squeeze cementing, penentuan kelayakan pekerjaan squeeze off \& shot top perforation dilakukan berdasarkan analisa keekonomian dengan menggunakan persamaan - persamaan sebagai berikut: (Lubiantara, 2012)

$$
\mathrm{NPV}=\sum_{t-l}^{n} C F_{0}+\frac{C F_{n}}{(1+i)^{n}}
$$

Dimana:

$\mathrm{CF}_{\mathrm{o}} \quad=$ Cash flow pada awal investasi

$\mathrm{CF}_{\mathrm{n}} \quad=$ Cash flow pada bulan ke-n

i $\quad=$ Discount rate

$\mathrm{n} \quad=$ Bulan ke-n

$$
\operatorname{IRR}=i_{1}+\left(\frac{N P V_{1}}{\left(N P V_{1}-N P V_{2}\right)}\right) \times\left(i_{2}-i_{1}\right)
$$

Dimana:

$$
\begin{array}{ll}
\mathrm{NPV}_{1} & =\text { Net Present Velue }(+) \\
\mathrm{NPV}_{2} & =\text { Net Present Velue }(-) \\
\mathrm{i}_{1} & =\text { Discount rate yang menghasilkan NPV (+) } \\
\mathrm{i}_{2} & =\text { Discount rate yang menghasilkan NPV (-) } \\
& \text { DPIR }=\frac{\sum \text { DiscountedNCF }}{\sum \text { Investasi }}
\end{array}
$$

Dimana: DPIR = Discounted profit to investment ratio (DPIR)

Pada analisis kelayakan ekonomi ini menggunakan sistem Production Sharing Contract (PSC) dalam pembagian keuntungan antara kontraktor dan pemerintah. Diagram dari PSC ini serta asumsinya dapat dilihat pada gambar di bawah. 


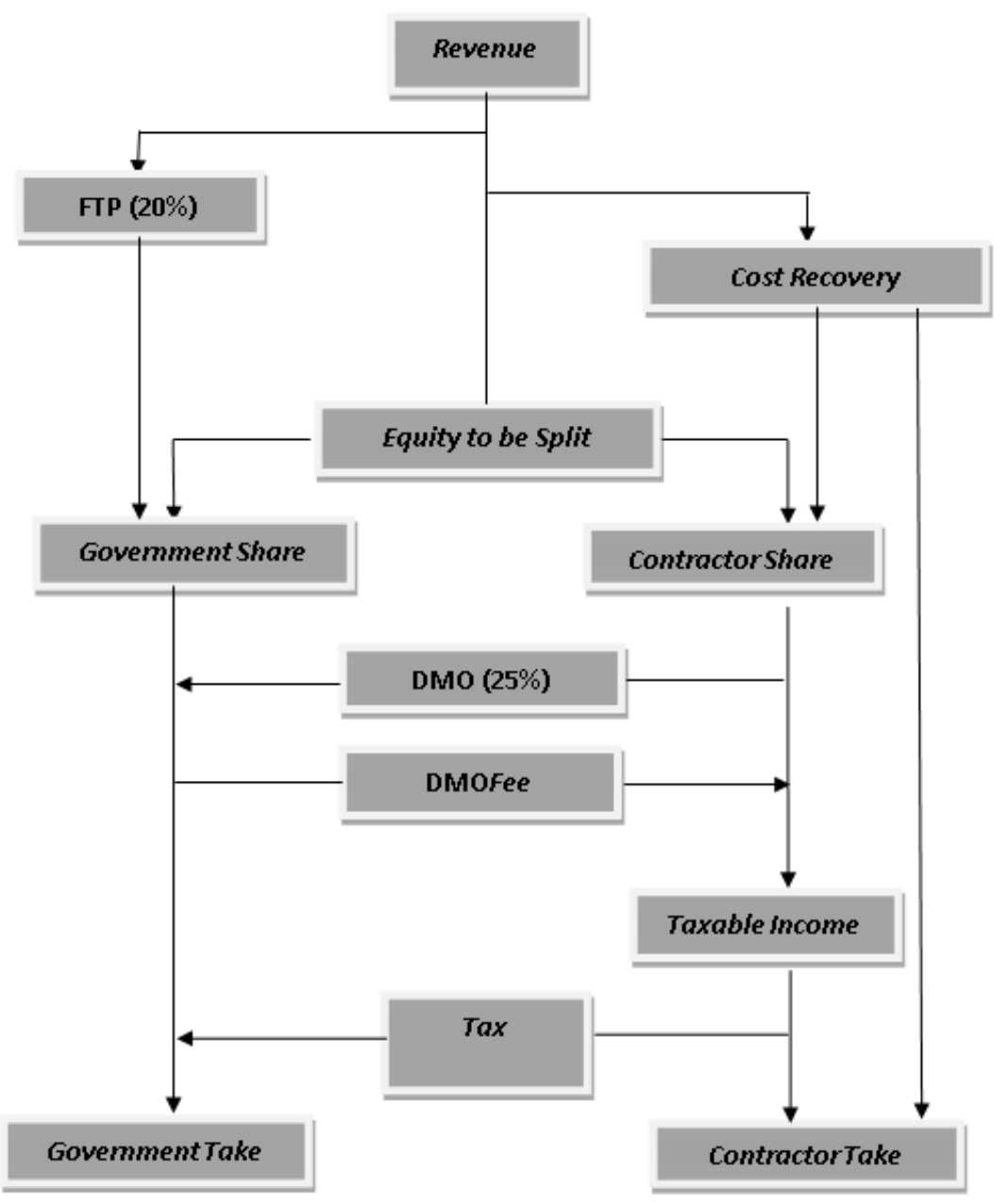

Gambar 1. Flow Chart Distribusi PSC (Benny Lubiantara, 2012)

Adapun data Anggaran Investasi dan Data Fiscal sesuai ketentuan kontrak keekonomian pada sumur MY05 dapat dilihat pada tabel 2 dan 3 berikut.

Tabel 2 Work Program and Budget dari Squeeze Off dan Shot Top Perforation

\begin{tabular}{ll}
\hline Non Capital Investment Budget & Price (US\$) \\
\hline Rig Contract & 29.106 \\
\hline Perforation and Completion Job & 25.000 \\
\hline Squeeze Job & 35.000 \\
\hline Packer & 10.000 \\
\hline Pump Cost & 10.000 \\
\hline Other & 5.000 \\
\hline TOTAL & 114.106
\end{tabular}

Pada tabel 2 di atas dapat dilihat bahwa keseluruhan biaya merupakan non-capital cost di mana tidak terdapat depresiasi. Pada pekerjaan squeeze cementing dan shot top perforation tidak ada capital cost dikarenakan alat yang digunakan (packer) pernah digunakan pada pekerjaan - pekerjaan sebelumnya sehingga depresiasi juga tidak ada. 
Novrianti/JEEE Vol. 6 No. 2/2017

Tabel 3 Parameter Keekonomian

\begin{tabular}{|c|c|}
\hline Economic Parameters & Rate \\
\hline Oil Price & US\$ 38/bbl \\
\hline Operating Cost & US\$ 10/bbl \\
\hline FTP & $20 \%$ \\
\hline DMO & $25 \%$ \\
\hline DMO Price & $25 \%$ \\
\hline Tax & $44 \%$ \\
\hline MARR & $15 \%$ \\
\hline Discount Rate & $15 \%$ \\
\hline
\end{tabular}

HASIL DAN PEMBAHASAN

Remaining Reserve sumur MY05

Tabel 4 berisi data dan hasil perhitungan Remaining reserve untuk setiap lapisan reservoir yang terdapat pada sumur MY05 yang berproduksi sejak tahun 1990 hingga tahun 2017:

Tabel 4 OOIP, Np, dan Remaining Reserve Setiap Lapisan Reservoir

\begin{tabular}{llll}
\hline \multirow{2}{*}{ Data Reservoir Dan Fluida } & \multirow{2}{*}{ Satuan } & \multicolumn{2}{c}{ Lapisan Reservoir } \\
\cline { 3 - 4 } & & $1440 '$ SD & $1460 '$ SD \\
\hline Area & ACRES & 64 & 32 \\
\hline Net Pay & FT & 32 & 28 \\
\hline Porosity & $\%$ & 31 & 33 \\
\hline Saturation, Water & $\%$ & 24 & 25 \\
\hline Formation Volume Factor & RB/STB & 1,078 & 1,078 \\
\hline OOIP & STB & 3.472 .452 & 1.607 .754 \\
\hline Net Production & bbl & 444.693 & 580.231 \\
\hline Remaining Reserve & STB & 3.027 .759 & 1.027 .513 \\
\hline
\end{tabular}

Berdasarkan Tabel 4 sumur MY05 masih memiliki remaining reserve yang cukup banyak terutama pada lapisan reservoir 1440' sand dibandingkan lapisan 1460' sand. Oleh karena itu, lapisan reservoir 1440' sand dipilih sebagai kandidat dilakukan pekerjaan squeeze off dan STP.

\section{Desain Squeeze Cementing}

Adapun data yang digunakan untuk melakukan perhitungan squeeze off dapat dilihat pada Tabel 5.

Tabel 5. Data Injectivity Test Pada Sumur MY05

\begin{tabular}{|c|c|c|c|c|c|}
\hline \multirow[b]{2}{*}{ No Sumur } & \multirow[b]{2}{*}{ Squeeze Interval } & \multicolumn{3}{|c|}{ Injectivity Test } & \multirow[b]{2}{*}{ Profil } \\
\hline & & Pressure (psi) & Rate (bpm) & $\begin{array}{l}\text { Vol } \\
\text { (bbl) }\end{array}$ & \\
\hline MY 05 & $\begin{array}{l}1538^{\prime}-1619^{\prime} \\
(7 \text { interval) }\end{array}$ & 900 & 2 & 30 & Tight \\
\hline
\end{tabular}

Berdasarkan Tabel 5 dapat dilihat bahwa jenis formasi adalah tight dari injectivity test yang dilakukan. Tekanan pemompaan sebaiknya berada dibawah tekanan formasi, hal ini dimaksudkan untuk menghindari terjadinya perekahan formasi oleh bubur semen dan menghindari terjadinya lost circulation (semen masuk ke formasi). Bubur 5 
semen mempunyai densitas besar sehingga memiliki tekanan hidrostatis yang lebih besar daripada tekanan reservoir. Untuk itu perlu dilakukan perhitungan bubur semen sebelum menjalankan squeeze off job. Dengan menggunakan persamaan 2 sampai dengan persamaan 7 diperoleh design squeeze off sebagai berikut:

Tabel 6. Hasil Perhitungan Desain Squeeze off Cementing

\begin{tabular}{llllllll}
\hline TOC & CIC & CIF & $\begin{array}{l}\text { Total } \\
\text { Cement } \\
\text { Slurry }\end{array}$ & $\begin{array}{l}\text { Jumlah } \\
\text { semen yang } \\
\text { dibutuhkan }\end{array}$ & $\begin{array}{l}\text { Air Bang } \\
\text { dibutuhkan }\end{array}$ & $\begin{array}{l}\text { Fracture } \\
\text { Pressure }\end{array}$ & $\begin{array}{l}\text { Total } \\
\text { Additif }\end{array}$ \\
\hline $1448 \mathrm{ft}$ & $6,9 \mathrm{bbl}$ & $\begin{array}{l}2,45 \\
\text { bbl }\end{array}$ & $9,35 \mathrm{bbl}$ & 46 sack & $5,4 \mathrm{bbl}$ & $1230,4 \mathrm{psi}$ & $1,27 \mathrm{bbl}$ \\
\hline
\end{tabular}

\section{Studi Kelayakan Ekonomi dari Squeeze Cementing dan Shot Top Perforation}

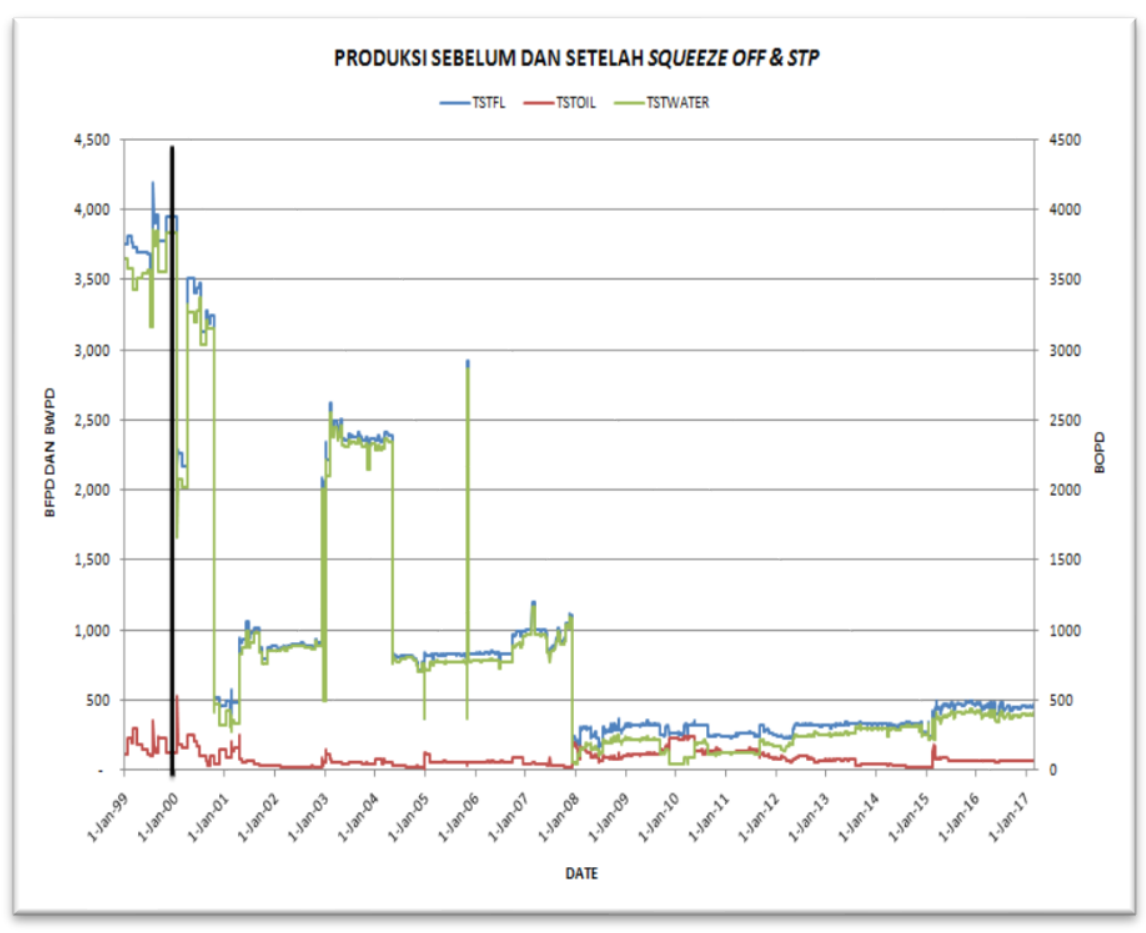

Gambar 2. Data Produksi Sumur MY05 Sebelum dan Sesudah Squeeze Off dan STP

Gambar diatas merupakan data produksi sumur MY05 yang diamati mulai dari bulan Januari 1999 hingga Februari 2017 yang menunjukkan produksi sumur MY05 sebelum dilakukan squeeze off \& shot top perforation dan produksi sumur MY05 setelah dilakukan squeeze off \& shot top perforation. Dari grafik diatas squeeze off \& shot top perforation dikatakan berhasil karena meningkatnya nilai produksi minyak dan diikuti dengan penurunan produksi air pada Januari 2000.

Berdasarkan Work Program and Bugdet (WP\&B) dan parameter keekonomian (Tabel 2 dan 3) dapat dilakukan analisis kelayakan ekonomi dari pekerjaan squeeze off dan shot top perforation yang dilakukan. Dari data - data tersebut dapat dilakukan perhitungan aliran dana atau Net Cash Flow (NCF) untuk mendapatkan NPV dari kedua pekerjaan yang dilakukan. 
Novrianti/JEEE Vol. 6 No. 2/2017

Tabel 7 Perhitungan NPV Aktual setelah Pekerjaan Squeeze Off dan Shot To Perforation

\begin{tabular}{lcl}
\hline \multirow{2}{*}{ Years } & \multirow{2}{*}{ NCF } & Discount Rate 15\% \\
\cline { 3 - 3 } & & Value \\
\hline 0 & -US\$114.106 & -US\$114.106 \\
\hline 1 & US\$202.734 & US\$176.290 \\
\hline 2 & US\$106.730 & US\$80.703 \\
\hline 3 & US\$33.108 & US\$21.769 \\
\hline 4 & US\$81.646 & US\$46.682 \\
\hline 5 & US\$55.131 & US\$27.410 \\
\hline 6 & US\$96.351 & US\$41.655 \\
\hline 7 & US\$97.303 & US\$36.580 \\
\hline 8 & US\$71.530 & US\$23.383 \\
\hline NPV & & US\$350.366 \\
\hline
\end{tabular}

Berdasarkan tabel 7 dapat dilihat bahwa setelah 8 tahun dilakukannya pekerjaan besarnya NPV dengan discount rate $15 \%$ adalah US $\$ 350.336$. Perhitungan IRR, POT dan DPIR dilakukan dengan menggunakan persamaan 9 dan 10 dan diperoleh hasil sebagai berikut:

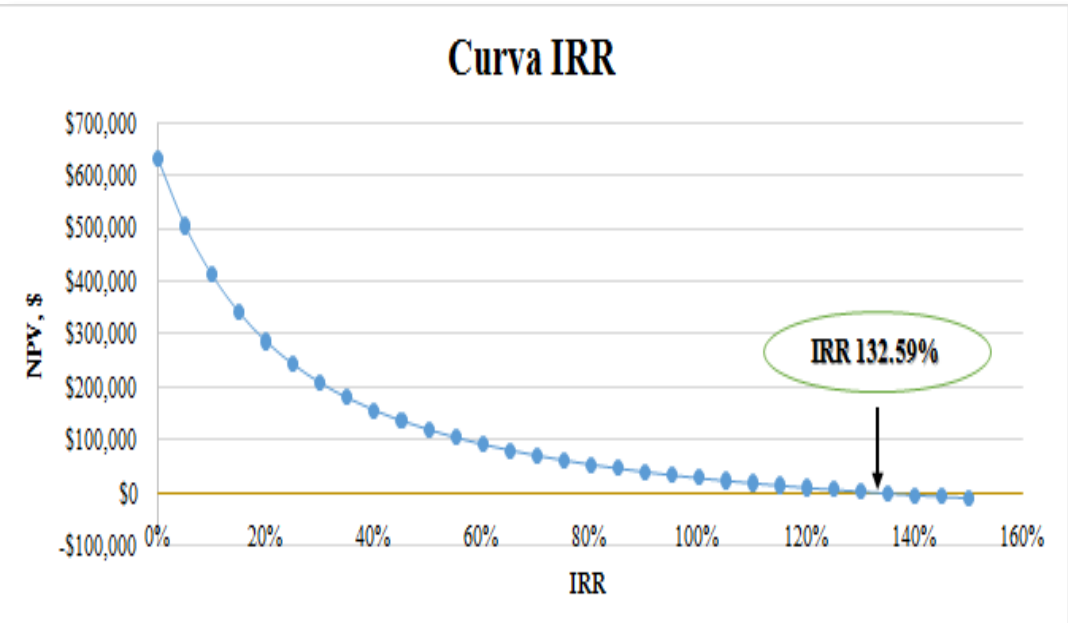

Gambar 3 Kurva Interpolasi IRR Actual Sumur MY05

Dilihat dari nilai Cummulated Net Cash Flow maka diperoleh nilai POT

$$
\begin{aligned}
& \text { POT }=\text { tahun } 0+\left(\frac{C N C F_{0}}{\left(C N C F_{0}-C N C F_{1}\right)}\right) \times(\text { tahun } 1-0) \\
& P O T=0,6 \text { Bulan }
\end{aligned}
$$

Dan Discounted Profit to Investment Ratio (DPIR)

$$
\begin{aligned}
& D P I R=\frac{N P V}{\text { Investasi }} \\
& D P I R=5,52
\end{aligned}
$$


Novrianti/JEEE Vol. 6 No. 2/2017

Gambar di atas menunjukkan nilai IRR saat NPV $=0$ berdasarkan interpolasi terhadap discount factor adalah 132.59\% dengan POT selama 0.6 bulan dan DPIR sebesar 5.52. Dari perhitungan kelayakan ekonomi pada sumur MY05, pekerjaan yang dilakukan dapat dikatakan layak karena NPV > 0, IRR > MARR, POT kecil dari umur proyek, dan DPIR > 1 .

\section{KESIMPULAN}

Berdasarkan perhitungan design squeeze off dan shot top perforation serta kajian keekonomian dari dua pekerjaan yang dilakukan pada sumur MY05, maka diperoleh kesimpulan sebagai berikut :

1. Design squeeze cementing yang digunakan untuk memperbaiki bonding cement sumur MY05 dibutuhkan 9.53 bbl slurry cement, 1.27 bbl additif

2. Perhitungan keekonomisan untuk sumur MY05 dalam kondisi actual diperoleh nilai NPV $15 \%=$ US $\$ 350.366, \mathrm{IRR}=132,59 \%, \mathrm{POT}=0,6$ bulan, $\mathrm{DPIR}=5,52$ dan berdasarkan hasil tersebut pekerjaan squeeze off dan shot top perforation layak untuk dilakukan.

\section{UCAPAN TERIMA KASIH}

Penulis ingin mengucapkan terima kasih kepada BOB PT. Bumi Siak Pusako - Pertamina Hulu atas izin dan dukungannya sehingga penelitian ini dapat terselesaikan.

\section{DAFTAR PUSTAKA}

Adams, N.J., Charrier, T., 1985. Drilling engineering: A complete well planning approach.

Bourgoyne, A.T, K. K. Millheim, M. E. Chenevert, F. S. Young. 1991. Applied Drilling Engineering. Society of Petroleum Engineers.

Daneshy, AA. 2006. "Selection and Execution Criteria for Water-Control Treatment". SPE Symposium and Exhibition on Formation Damage Control held in Lafayette, 15-17 February 2006. Los Angeles.

Engler, T.W., Brister, B., Place, L., Siegfried, R.W., 2004. Identification of behind-pipe pay zones in low permeability sand / shale / coal sequences.

Lubiantara, Benny. "Ekonomi migas - Tinjauan aspek komersial kontrak migas”, Analisa Kebijakan Fiskal OPEC, Jakarta, 2012.

P.Roberts, T.O.A.\& A., 1982. Well completion, work over and stimulation. Oil \& Gas Consultans International, Inc.pdf.

Partowidagdo, W., 2002. Manajemen dan Ekonomi Minyak dan Gas Bumi.pdf.

Thomas W.Engler and Brian Bister (2004). "Identification of behind pipe Pay zone in low permeability sand/shale/coal seqences". Mexico, Tech.

Zulhendra, 2008. Studi karakteristik sumur dan reservoir yang mempengaruhi alokasi produksi. Stud. Karakteristik sumur dan reserv. Yang mempengaruhi alokasi produksi.

Widi E, Bambang, (2004) Well service \& workover, Yogyakarta : Wahana Pengembangan Manajemen. 